(A)

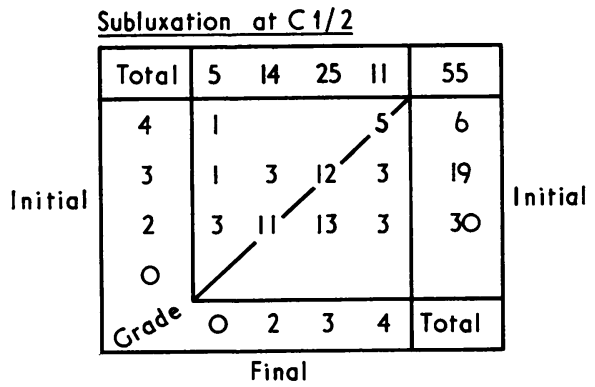

Subluxation below $\mathrm{C2}$

\begin{tabular}{|c|cccc|c|}
\hline Total & 18 & 25 & 9 & 3 & 55 \\
\hline 4 & & & & & \\
3 & 2 & 5 & 3 & 1 & 11 \\
2 & 16 & 20 & 6 & 2 & 44 \\
0 & & & & & \\
$\mathrm{crode}^{8}$ & 0 & 2 & 3 & 4 & Total \\
\hline \multicolumn{5}{c|}{ Final } \\
\end{tabular}

(B)

DR. P. H. N. WOOD (Manchester) The value of death certificates is often challenged. However, whether someone is alive or dead is a simple question, that can be answered accurately. It is useful to know whether patients of a particular type, such as those with cervical subluxation, have an increased mortality. We should make more use of this simple indicator of whether a particular condition is important in terms of survival.

Finger Flexion in Rheumatoid Arthritis. By JoHN Colville (Consultant Plastic Surgeon, Royal Victoria Hospital, Grosvenor Road, Belfast BT12 6BA).

The term dyscampsia has been created to describe disability in finger flexion from whatever cause. In rheumatoid arthritis there are many causes of this condition and it is pointed out that these must be diagnosed precisely if those amenable to surgery are to be selected.

In considering the cause of dyscampsia the finger is viewed structurally. Increase in the bulk of the subcutaneous tissue which is often seen in acute inflammatory conditions prevents flexion and can be relieved only by reduction of the tension within the finger.

Dyscampsia due to tendon disease may be classified as follows:

(1) Paralytic

This includes disuse atrophy, rheumatoid myopathy, and motor nerve compression.

(2) Disruptive

This occurs mainly under the pulley areas of the digits and underneath the carpal tunnel. Partial disruption with cross adhesion may obscure the issue.

\section{(3) Obstructive}

(a) Incipient or partial when the excursion of the tendon is impeded;

(b) Intermittent when it is occasionally completely obstructed;

(c) Fixed when the tendon is no longer able to pursue its normal excursion at that point.

\section{(4) Imbalanced}

In this situation the weak flexor is unable to overcome the spasm or contracture of the intrinsic extensors.

Tendons are much more amenable to surgery than joints, and once a diagnosis has been established the appropriate surgical procedure gives good results with minimal inconvenience to the patient.

Dyscampsia may be directly due to joint disease. The denervation of a prophylactic synovectomy may render a painful joint functional again. At the other end of the scale the insertion of silastic joints is of considerable value in salvage procedures. Between these extremes of joint 
pathology there is little that can be offered to the patient surgically. In the author's practice of rheumatoid hand surgery, in which surgical effort was initially directed at joint disease, there has been a gradual change of emphasis to the treatment of soft tissue rehumatism in which the tendon has become the focal point. The rapid easy rehabilitation following tendon surgery makes this more attractive and, where resources are limited to dealing with a fraction of the potential demand for surgery, it seems logical to concentrate on this aspect.

DR. B. M. ANSELl (Taplow) Have you had any tendon ruptures after extensive clearance or fibrosis requiring reexploration?

MR. COLVILLE I think that synovectomy produces an environment in which a tendon can pick up a fresh blood supply. I have not seen tendon rupture after synovectomy. Regarding adhesions, this is not a troublesome feature of this type of surgery and certainly causes much less dysfunction than the trapped tendon.

Fluorine-18 Isotope Scans of the Sacroiliac Joints. By J. WebB, L. T. Collins, P. B. Southwell, and J. B. DickSMITH (Sutton Rheumatism Research Laboratory and Departments of Nuclear Medicine and Radiology, The Royal North Shore Hospital of Sydney, Australia).

Using a linear collimator and 2 to $3 \mathrm{MiC}$ Fluorine-18, postero-anterior scans of the lumbar spine and pelvis were performed in 22 cases of ankylosing spondylitis and other diseases (Table), in which a radiological diagnosis of sacroiliitis is frequently difficult to establish.

Table Diagnosis in 22 cases

\begin{tabular}{|c|c|c|c|c|c|}
\hline Diagnosis & $\begin{array}{l}\text { No. of } \\
\text { cases }\end{array}$ & $\begin{array}{l}\text { Clinically } \\
\text { active } \\
\text { sacroiliitis }\end{array}$ & $\begin{array}{l}\text { Positive } \\
18 F \\
\text { scan }\end{array}$ & $\begin{array}{l}\text { Positive } \\
\text { routine } \\
\mathrm{x} \text { ray }\end{array}$ & $\begin{array}{l}\text { Positive } \\
\mathrm{x} \text { ray on } \\
\text { review }\end{array}$ \\
\hline $\begin{array}{l}\text { Ankylosing spondylitis } \\
\text { Reiter's disease } \\
\text { Psoriatic arthritis } \\
\text { Rheumatoid arthritis } \\
\text { Septic arthritis }\end{array}$ & $\begin{array}{r}12 \\
5 \\
2 \\
2 \\
1\end{array}$ & $\begin{array}{l}6 \\
2 \\
0 \\
1 \\
1\end{array}$ & $\begin{array}{l}9 \\
3 \\
1 \\
1 \\
1\end{array}$ & $\begin{array}{l}\mathbf{5} \\
\mathbf{3} \\
\mathbf{0} \\
\mathbf{0} \\
\mathbf{1}\end{array}$ & $\begin{array}{r}11 \\
5 \\
1 \\
2 \\
1\end{array}$ \\
\hline Total & 22 & 10 & 15 & 9 & 20 \\
\hline
\end{tabular}

Positive scans were obtained in fifteen cases, including nine of ten with clinically active sacroiliitis, and another five cases in which the diagnosis made would usually be associated with sacroiliitis, though clinical findings were absent. In the seven whose sacroiliitis had become clinically inactive, the scans were positive in only one case. Clinically active lumbar spondylitis in three cases was also evident on scanning.

Sacroiliac radiographs were reported abnormal in only nine cases. Careful reassessment showed early changes to be present in another eleven, which would easily have been overlooked in many.

Besides their value in helping to substantiate the diagnosis of sacroiliitis, especially early in the disease when $x$ rays are often equivocal, Fluorine-18 scans might be used to follow the progress of disease and its response to therapy.

\section{Discussion}

PROF. V. WRIGHT (Leeds) How do you define clinically active sacroiliitis and how long does the test take?
DR. WE B B Scanning starts 20 minutes after the injection and is completed approximately 20 minutes later.

We accepted the presence of a positive clinical test for sacroiliac inflammation, or a good history of sacroiliac pain.

PROF. E. G. L. BYWATERS (Taplow) How do you assess positive scans and with what background are they compared?

DR. WEBB We have a number of normal subjects. We are looking for an increased or unequal uptake between the sacroiliac joints and the lumbar spine. The scanner was centred initially on the mid-point of the lumbar spine with constant setting of the scanner parameters and the background suppression.

PROF. E. G. L. BYWATERS (Taplow) If you had lumbar spine disease would this not affect it?

DR. WEBB We had three patients with lumbar spine disease and this was evident, although sacroiliac uptake exceeded that of the lumbar spine. Normal and abnormal scans were randomized and read twice with matching results.

DR. D. HASLOCK (Leeds) I have recently read 2,000 sacroiliac $x$ rays and am impressed by the number of small abnormalities present in apparently normal subjects. By applying your fine criteria to the normal population, how many would you consider had sacroiliitis?

DR. WEBB Fifty randomized $x$ rays, including a selection from this patient group, were read by the clinicians and the radiologist. There was a 95 per cent correlation in assessment of abnormality.

Effect of Hydrocortisone on Regeneration of Synovium and on Articular Surfaces after Synovectomy in Rabbits. By G. Bentley (Nuffield Orthopaedic Centre, Oxford)

Many clinical studies have indicated the beneficial effect of synovectomy in rheumatoid arthritis performed at an early stage before articular cartilage destruction is advanced, particularly in the knee and the metacarpophalangeal joints of the fingers (Marmor, 1966; Mason, 1969; Preston, 1969; Paradies, 1969). These studies have suggested that articular cartilage damage is delayed or even prevented by synovectomy. However, recent reports by Brånemark, Ekholm, Goldie, and Lundskog (1969), Geens, Clayton, Leidholt, Smyth, and Bartholomew (1969), and Bartholomew (1970) have demonstrated that after synovectomy for rheumatoid arthritis the regenerated synovium showed histological appearances suggesting a recurrence of the rheumatoid process and increased amounts of lysosomal enzymes, as in the original diseased membrane.

It would be desirable to prevent recurrence of the disease in the regenerated synovial membrane after synovectomy without prejudicing the joint cartilage.

An experiment was carried out in which synovectomy was performed on seventy mature male New Zealand white rabbits. In half the animals $25 \mathrm{mg}$. hydrocortisone acetate was injected weekly intramuscularly to study the effect on the regeneration of synovium and on articular cartilage. The animals were killed at intervals of from 4 to 110 days. Synovial regeneration was considered complete when there was re-formation of a surface layer one to three cells thick, abundant capillaries subjacent to the 